\section{Hanging in the balance}

\section{Could the UK's long awaited screening programme for bowel cancer become a victim of the NHS's financial crisis? Rebecca Coombes reports}

Until last Christmas everything seemed to be going well for those involved in the field of bowel cancer. Funding for a national screening programme for the condition, the second most common cause of death from cancer in the United Kingdom, had been agreed back in October 2004. The $£ 34 \mathrm{~m}$ $(\$ 60 \mathrm{~m} ; € 50 \mathrm{~m})$ initiative, the first of its kind in Europe, is due to be rolled out in April to everyone in England aged between 60 and 69 years old.

But experts have become anxious that, at the 11th hour, the programme could be a victim of the current spending crisis in the NHS. Although the Department of Health says it is committed to the roll-out, no assurance has been given that the agreed funding will be protected.

Bowel cancer kills about 16000 people a year in the UK. The high mortality is attributed to late detection of the disease. Only $8-10 \%$ of the cancers are currently caught at an early stage, at which point survival is as high as $90 \%$. Studies show that the screening programme could push early detection up to $27 \%$ of all cases.

The National Screening Committee estimates that the programme could save the lives of around 1200 people a year in England alone, which represents a reduction of about $9 \%$ in the 13000 annual death toll.

One senior clinician said he would be most concerned if the rumours concerning the future of the screening programme turn out to be true, as it is backed by

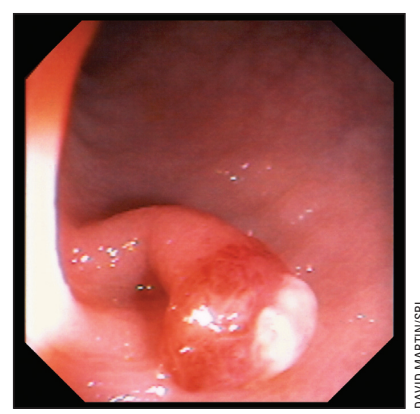

Early detection of cancerous polyps (above) could save 1200 lives a year in England sound evidence and has the potential to be as successful as breast cancer screening.

Rob Glynne-Jones, a lead clinician for gastrointestinal cancer at the Mount Vernon Cancer Centre and a medical adviser to Bowel Cancer UK, said: "I speak as a cancer specialist dealing with a large number of patients whose cancer has already spread beyond the confines of the bowel and is incurable. This is really crucial for future generations. It [the programme] is far too important to go down the tubes at the whim of politicians."

He said that screening also brought with it other benefits, such as a greater awareness of symptoms and advice on lifestyle changes that could lower risk.

The programme would see home testing kits sent to people in the target age bracket every two years. The faecal occult blood test, which costs $£ 5$, can detect blood in stools and would prevent the embarrassment of going to the doctor to give a sample. In pilots, $2 \%$ of the tests were positive and led to a diagnostic colonoscopy.

Concerns have been expressed that the NHS will not be able to cope with the number of extra colonoscopies needed as a result of the screening programme, a problem exacerbated by the fact that the test gives a high number of false positive results. One major London hospital, for example, already has an average wait of 12 months for non-urgent colonoscopies. It is not clear where such hospitals are going to find the staff to perform the extra investigations, nor how doctors can protect the interests of those patients who need colonoscopies but who are not in the screening programme.

Dr Glynne-Jones said: "No, we don't have the infrastructure yet, but Mike Richards [the national director for cancer] was astute because he said, 'OK, let's start looking at the programme for people who are 60 plus and work towards building up the infrastructure and then bring the screening age down to 55.' It is a staged approach. If we don't get a screening programme off the ground we may never get the infrastructure."

David Cunningham, a consultant medical oncologist and head of the gastrointestinal unit at the Royal Marsden NHS Foundation Trust, agrees. "The faecal occult blood test does have resource implications, but this is not a con-

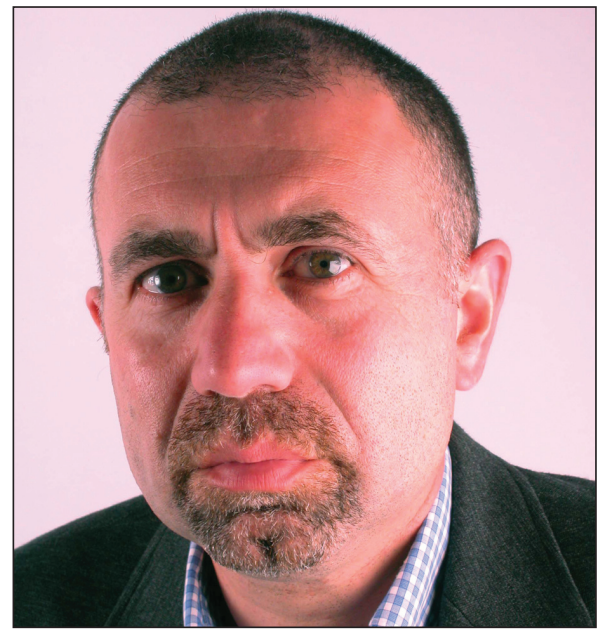

troversial test, Peter Baker, chief executive of the Men's Health [because] as an Forum, said the programme was the only cancer intervention it is screening scheme to include men worth while. You

get a good return

for your investment because this is based on trial data that shows it does improve survival," he said.

The screening programme has been piloted in two sites in the UK, one in England (Coventry and Warwickshire) and one in Scotland (Fife, Tayside, and Grampian). Each site covers around 1.5 million people. The screening programme is due to be rolled out in 2007 in Scotland and will target people there aged between 50 and 69 .

Leslie Samuel, a consultant oncologist at the Aberdeen Royal Infirmary, said that results from the Scottish pilot have shown a reduction in mortality of $16 \%$ among patients with colorectal cancer. He said, "This reduction is in line with previously published data from the United States, Denmark, and Nottingham. We are very pleased with the results. In Grampian we have a higher than average instance of bowel cancer, and we have been detecting far more polyps than was previously predicted."

Meanwhile a large clinical trial into the benefits of another model for screening for bowel cancer, using a flexible sigmoidoscope, is not due to report until 2007. The model is cheaper and logistically simpler than the one due to be rolled out in April because it involves inviting all 55 to 60 year olds for a one-off test that just looks at the lower part of the bowel and rectum. But it is not yet known how effective it is at saving lives.

With around six weeks to go to the roll-out in England, Bowe Cancer UK has been urgently seeking assurance from the secretary of state for health, Patricia Hewitt, that the planned screening programme will go ahead. Ian Beaumont, a spokesman for the charity, said a letter sent to Ms Hewitt's office in December had so far been ignored.

He said, "It's very last minute to be saying the resources aren't in place. Preparations should have been made years ago and not just put on the shelf. We are trying to be quietly hopeful. The April launch was always going to be fairly low key, as only two of the five planned laboratories to analyse the testing kits are ready to go."

The Men's Health Forum said it was anxious to protect the screening programme, the first in the United Kingdom to include men. In a letter to Ms Hewitt, the forum's chief executive, Peter Baker, said: "The programme has the potential to make a major contribution to tackling gender health inequalities in cancer. Time is at a premium, and any further delay in confirming funding will be hugely detrimental."

A health department spokesperson said: "The government has stated its commitment to a national bowel cancer screening programme. On 30 January 2006 the new health white paper, Our Health, Our Care, Our Say: A New Direction for Community Services, reaffirmed that the programme will be rolled out from April 2006. Department of Health budgets for 2006-7 are currently being finalised, and announcements will be made in due course." $\square$ Rebecca Coombes London 